\title{
FORMAÇÃO INICIAL E PERMANENTE DO PROFESSOR DE ARTE NA EDUCAÇÃO BÁSICA
}

\author{
MARIA EMILIA SARDELICH \\ Departamento de Educação da Universidade Estadual de Feira de Santana \\ milisar@uol.com.br
}

\section{RESUMO}

Este trabalho expõe uma pesquisa descritiva realizada em 1998 com professores de Educação Artística que atuam na educação básica do municipio de Feira de Santana, na Bahia. Conhecer esses professores e a sua prática cotidiana foram os objetivos propostos por esta pesquisa. Por meio de formulários com itens abertos e fechados, levantaram-se dados sobre a formação, tanto inicial quanto permanente, suas condições e concepções de trabaIho. Evidenciaram-se a falta de formação especifica dos profissionais, as precárias condições de carreira e trabalho bem como ambigüidades apresentadas nas concepções de arte analisadas. O trabalho discute também a formação permanente desse professor como ação cultural a fim de se democratizar o acesso à arte.

FORMAÇÃO DE PROFESSORES - ARTE - EDUCAÇÃO BÁSICA - EDUCAÇÃO ARTISTICA - ARTE-EDUCAÇÃO

\begin{abstract}
THE INITIAL AND PERMANENT FORMATION OF THE ART TEACHER IN THE BASIC EDUCATION. This article presents the results of a research realized with Art teachers who works with basic education in the city of Feira de Santana (BA). The research collected data about the initial and permanent formation of the Bahia's teachers, work conditions and Art's conceptions with a set of questions requiring specific answers and open-ended as well, during the period between March and December of 1998. They evidenced those teachers' not specific formation, the faulty aspects of the initial formation, the precarious career conditions and work, besides ambiguous conceptions on the Art teaching. The researches discussed the permanent formation of those teachers, as cultural action, so that is possible the development of a work that democratizes the access to the Art without restriction to any space or private human group.
\end{abstract}


A atual Lei de Diretrizes e Bases da Educação Nacional - LDBEN - n. 9.394/ 96 estabelece em seu artigo 26, parágrafo segundo, a Arte como conteúdo curricular obrigatório nos diversos níveis da educação básica. Conseqüente à ultima edição da LDBEN, o Ministério da Educação e do Desporto editou, em 1997, os Parâmetros Curriculares Nacionais - PCNs - a fim de apontar metas de qualidade para a educação do cidadão participativo, reflexivo, autônomo e conhecedor de seus direitos e deveres. Esses parâmetros foram elaborados para servir de referência ao trabalho do professor, respeitando-se a concepção pedagógica própria e a pluralidade cultural brasileira.

Segundo o discurso oficial, os Parâmetros Curriculares Nacionais são um instrumento para a elaboração de projetos educativos, planejamento de aulas, reflexão sobre a prática educativa e análise do material didático. De acordo com estes, a Arte desempenha função tão importante quanto à dos outros conhecimentos no processo de ensino e aprendizagem e, apesar de estar relacionada com todas as demais áreas, tem suas especificidades e é tratada como área diferenciada.

A educação em arte propicia o desenvolvimento do pensamento artístico e da percepção estética, que caracterizam um modo próprio de ordenar e dar sentido à experiência humana: o aluno desenvolve sua sensibilidade, percepção e imaginação, tanto ao realizar formas artísticas quanto na ação de apreciar e conhecer as formas produzidas por ele e pelos colegas, pela natureza e nas diferentes culturas. Esta área também favorece ao aluno relacionar-se criadoramente com as outras disciplinas do currículo. (Brasil, 1997, p.19)

Uma vez tendo esse horizonte de qualidade a ser alcançado com o trabalho de Arte na educação básica brasileira, como professora de Arte perguntei-me sobre as condições existentes para atingir as metas definidas pelo governo federal. O tema da qualidade do ensino está diretamente vinculado à formação do professor. Segundo os Parâmetros Curriculares Nacionais, todos os professores de Arte deveriam poder responder às questões que fundamentam a atividade pedagógica, como o tipo de conhecimento que caracteriza a Arte e sua função na sociedade; a contribuição da Arte para a educação e o ser humano, além de definir como se aprende a criar, experimentar e entender Arte. Os professores de Arte que atuam nas escolas de educação básica estão preparados para responder às questões propostas pelos Parâmetros Curriculares Nacionais?

Como professora da Universidade Estadual de Feira de Santana, Bahia, decidi conhecer esse professor mediante sua formação inicial e permanente, suas 
condições de trabalho, pois parti do princípio de que essa compreensão nos poderia dar melhores perspectivas para lidarmos com a tão desejada qualidade da educação básica brasileira. Optei pelo estudo com os professores da rede estadual por serem as Universidade Estadual de Feira de Santana e o Centro de Aperfeiçoamento e Desenvolvimento da Ciência e Tecnologia - CADCT - entidades financiadoras desta pesquisa, mantidas pela mesma esfera do poder público. Nos comprometemos com a melhoria da qualidade do ensino público de um modo geral e, particularmente, com o desta rede de ensino. Segundo Gil ( 1987), pesquisadores preocupados com a atuação prática costumam realizar pesquisas descritivas. Nos incluímos nesse caso, pois buscamos conhecer as características desse professor para desenvolvermos futuros projetos em comum, entre nossa universidade e a rede estadual de ensino.

A coleta de dados realizou-se entre os meses de março e novembro de 1998, por meio de formulários com itens abertos e fechados. A Diretoria Regional de Ensino nos forneceu o número de escolas de educação básica da cidade de Feira de Santana. Esse universo se compõe de 96 escolas assim classificadas: 4 escolas de porte especial (com mais de 25 salas), 6 de porte grande (de 16 a 25 salas), 45 de porte médio (de 8 a 15 salas) e 4 I escolas de porte pequeno (até 7 salas de aula).

estudo cobriu 25\% desse universo, ou seja, foram visitadas 24 escolas assim distribuídas: 3 escolas de porte especial, 6 de porte grande, II de porte médio e 4 escolas de porte pequeno. Privilegiaram-se as visitas às escolas de maior porte por suposição inicial de que essas apresentariam uma maior incidência de licenciados em Educação Artística. Essa suposição se fundamentou no seguinte raciocínio: de um lado o Parecer 1.284/73 do Conselho Federal de Educação criou o curso de Educação Artística, pretendendo a formação do professor polivalente em Arte; por outro, a edição anterior da Lei de Diretrizes e Bases da Educação Nacional n. 5.692/7I limitava a atuação do licenciado a partir da 5 a série do antigo primeiro grau, atual ensino fundamental. Dado que as escolas de porte pequeno da região atuam apenas da $I^{\mathrm{a}}$ à $4^{\mathrm{a}}$ série do ensino fundamental, optamos por visitar apenas 10\% dessas escolas, por supormos que nelas encontraríamos menor número de licenciados, foco de nosso interesse neste trabalho. Ao longo das visitas pudemos confirmar a nossa suposição.

A partir de dados colhidos com diretores e vice-diretores das 24 escolas visitadas, estas contariam com 69 professores de Educação Artística. Visitamos essas 24 escolas em todos os seus turnos de atendimento e em diferentes dias da 
semana e horários, porém não nos foi possível encontrar a totalidade desses prováveis 69 professores. Utilizo aqui a expressão prováveis, pois muitas vezes os diretores duvidavam no momento de informar sobre a quantidade de professores de Arte em exercício na escola e não possuíam nenhum tipo de registro que pudesse confirmar tal dado. Supomos que os gestores não afirmavam com segurança o número de professores de Arte pelo fato de esses professores atuarem, em sua grande maioria, com outros conteúdos curriculares, entre os mais freqüentes em Feira de Santana: Educação Física, Português, Ciências, Matemática, Geografia, História e Religião.

Constatamos que uma das grandes dificuldades que enfrenta o sistema de ensino é a falta de informação a respeito do mesmo, quem o integra, quem o faz materializar-se, apesar dos periódicos censos educacionais realizados pelo poder público. Obter uma informação correta de forma rápida e segura é árdua tarefa na instituição escolar, sobretudo a respeito de professores efetivos em exercício. Em Feira de Santana, isso se deve à contínua substituiç̧ão de professores efetivos em licença por estagiários, estudantes de qualquer graduação aceitos na função de professores de qualquer conteúdo curricular sem a devida formação para tal.

Apesar de todos os esforços realizados para encontrarmos os 69 prováveis professores de Arte, só nos foi possível localizar 53 professores que efetivamente atuam nas 24 escolas visitadas que compuseram nossa amostra, ou seja, 25\% do total de unidades de educação básica do Município de Feira de Santana.

\section{INFORMAÇÕES BÁSICAS}

Dos 53 professores que responderam ao formulário, 96\% são do sexo feminino e $4 \%$ do sexo masculino. Com esse dado, justifico o fato de que a partir deste ponto, utilizarei o plural sempre no feminino, mesmo que as regras gramaticais indiquem que entre gêneros diferentes prevaleça o masculino. Alguns estudos já têm apontado para a maciça presença da mulher no magistério e que uma das possíveis razões para o fenômeno seja a ideologia patriarcal de aceitar essa atividade extradoméstica como uma ocupação transitória (Enguita, 1991). A idade média dessas professoras está em torno dos 43 anos de idade, com II anos de permanência média na escola que ora atuam. Possuem 16 anos de experiência no magistério, porém apenas dois anos em Educação Artística.

Indagadas sobre o hábito da leitura em suas vidas, 94\% afirmaram ler alguma revista; $4 \%$ não lêem e 2\% declararam que lêem de vez em quando. Listamos 
as revistas citadas em ordem decrescente pelo número de referências: Veja, IstoÉ, Caras e Superinteressante. A regularidade de leitura concentra 34\% semanalmente; 38\% mensalmente; 22\% sem regularidade e 6\% não respondeu à questão.

Quanto à leitura de livros, 77\% afirmaram praticá-la regularmente, enquanto $19 \%$ declararam não realizar essa atividade devido à falta de tempo e ao custo dos livros; $2 \%$ lêem às vezes e outros 2\% não responderam à questão. Os títulos foram os mais variados, Verdade tropical, de Caetano Veloso, foi citado por duas professoras; outras duas liam contos de Clarice Lispector enquanto outro par lia Vidas secas, de Graciliano Ramos, e duas mais Sagarana, de Guimarães Rosa. Outras dez professoras citavam livros espirituais e de auto-ajuda, entre estes: $A$ Bíblia, O Livro dos médiuns, Os Dons dos espiritos, $A$ Vida começa aos quarenta e nove, A Águia e a galinha, de Leonardo Boff, e À Margem do Rio Pietra, de Paulo Coelho. As demais pesquisadas, 35 professoras, ou seja, 66\% não lembravam o título do último livro lido. Quanto à periodicidade dessa leitura, $21 \%$ não responderam a questão; I $5 \%$ estavam lendo na época; 19\% haviam terminado a leitura há um mês; 23\%, há dois meses; 13\% terminaram a leitura entre três a seis meses e $9 \%$, entre sete meses e um ano.

Leitura específica, representada por revista ou livro de educação, mobilizava $88 \%$ das professoras; $8 \%$ declararam não ler; $2 \%$ lêem às vezes e outros $2 \%$ não responderam à questão. A leitura específica das professoras pesquisadas concentra-se em revistas de educação, pois livros de educação não foram mencionados, apenas uma professora citou os Parâmetros Curriculares Nacionais, e entre estes o de Arte, como livro de educação que lia na época. As revistas especializadas, aqui mencionadas em ordem decrescente por número de referências, foram: Nova Escola, Revista do Professor, Revista de Educação Física e Desporto. A periodicidade dessa leitura especializada se concentra em $26 \%$ mensal; $32 \%$ bimensal; I3\% de dois a seis meses; 29\% entre sete meses e um ano.

Os dados a respeito da leitura realizada pelas professoras nos remetem à questão da formação. A formação passa, também, pela iniciativa da professora em buscar informações e realizar leituras. É indispensável ao profissional da educação seu comprometimento com o conhecimento e sua busca constante. É imprescindível a consciência de que o que se sabe nunca é suficiente; mesmo que cada profissional conte com conhecimentos específicos de sua área, ele necessita se apropriar de conhecimentos comuns de outras áreas. Este é um dado que exige reflexão. As professoras pesquisadas se declaram leitoras, mas podemos perceber que a atividade de leitura especializada não tem sido intensa, restringindo-se, basi- 
camente, à revista Nova Escola, que se dedica a divulgar fórmulas supostamente consagradas de conduta pedagógica. Também surpreende o fato de que 64\% não fossem capazes de recordar o título do último livro lido. A leitura é, sem dúvida, um meio de se obter informação, mas ela está igualmente relacionada ao prazer pessoal. Lemos para aprender, para saber, para compreender, para refletir, mas lemos, também, pela beleza da linguagem, lemos para nossa emoção. Diante desses dados cabe nos perguntarmos sobre a leitura que essas professoras deveriam efetuar ao longo da vida profissional.

\section{FORMAÇÃO PROFISSIONAL}

Para o estudo da formação profissional dessas professoras, buscou-se verificar se existiria algum movimento em sua trajetória instrucional em relação à família de origem. Cerca de 64\% dos pais cursaram o ensino fundamental; $23 \%$, o ensino médio e $13 \%$ não são escolarizados, com ocupações que envolvem a agricultura, o comércio e o funcionalismo público. As mães apresentam nível escolar mais elevado, pois $62 \%$ completaram o nível fundamental; $23 \%$, o médio; $4 \%$, o superior e 1 | \% não tiveram oportunidade de escolarização. As mães se ocupavam das tarefas domésticas, porém 5\% exerceram, em algum momento, o magistério. Percebemos movimento ascendente no processo de escolarização das professoras em relação às suas famílias de origem.

Entre as professoras participantes da pesquisa, 55\% possuem a formação superior e 45\%, a média. O nível superior foi acessível a 86\% dessas licenciadas em instituições públicas, enquanto 14\% cursaram-no em instituições privadas. Concentramos nossa atenção na formação específica das professoras e, entre os 55\% de nível superior, apenas 10\% cursaram Licenciatura em Educação Artística; 45\% provêm de Letras; 15\%, de Estudos Sociais; 7\%, de Pedagogia; 7\%, de Ciências Contábeis; 7\%, de Ciências; 3\%, de Biologia; 3\%, de Geografia e outros $3 \%$, de História. Vale ressaltar que apenas 10\% das professoras com nível superior que se ocupam das atividades artísticas nas escolas visitadas procedem dos cursos de Licenciatura em Educação Artística, porém se relacionarmos estas com a totalidade das professoras pesquisadas, se não discriminarmos o seu nível, a porcentagem de professoras com formação específica cai para 5\%.

Indagadas em sobre como chegaram a trabalhar como professoras de Educação Artística, entre todas as professoras, ou seja, com formação média e superior, 55\% declararam a necessidade de complementar a carga horária; 17\%, por intermédio do curso de adicionais, I $\%$ declararam que por acaso, sem especifi- 
car; $8 \%$, por dom, por jeito, por gostar de artesanato e 5\%, por escolha profissional. Percebe-se que a Educação Artística na vida dessas professoras aconteceu, ou seja, não representou uma opção entre várias outras, decorrente de uma escolha específica. Esse dado demonstra a desconexão entre a professora e sua área de atuação.

Buscamos identificar, na opinião das professoras, quais os aspectos mais deficientes da sua formação inicial e, dentre os mais freqüentes, foram mencionados: a ausência da prática da sala de aula que se traduz tanto na habilidade de domínio da sala quanto na habilidade de adequar conteúdos à realidade vivida pela clientela escolar; a escassa compreensão e domínio das leituras realizadas; o pouco entendimento dos aspectos psicológicos envolvidos nas relações humanas, nos grupos em geral e não apenas com as crianças; a rara conexão entre teoria e prática; a falta de comunicação existente entre professor e aluno que se faz representar por sentimentos de opressão; o privilégio de um ensino "decoreba" avesso à produção do conhecimento; a dificuldade do acesso aos livros; a carência de aulas de desenho, canto e teatro.

Não costumamos atentar para o fato de que gerir as atividades de aula implica saber manter o equilíbrio entre as iniciativas individuais dos estudantes, as atitudes do professor e do grupo, criando, assim, um ambiente propício a uma aprendizagem que envolve o trabalho simbólico de "significar", de atribuir sentido ao que se propõe conhecer. Para tanto, é fundamental a interação entre todos os implicados no processo como co-responsáveis pelo sucesso da aprendizagem. As habilidades básicas de ouvir, criar, decidir, resolver problemas, somadas às qualidades pessoais de auto-estima e sociabilidade, não costumam ser consideradas nos cursos de formação. Cabe observar, também, que entre os pontos deficientes levantados, as professoras destacam a compreensão dos aspectos psicológicos envolvidos nas relações humanas. Sabemos que os cursos de licenciatura focalizam, prioritariamente, a psicologia do desenvolvimento. Esta corrente tem-nos habituado a pensar a criança na perspectiva de um organismo em formação, que se desenvolve por estágios, dentro de uma certa cronologia.

É bastante comum os educadores confundirem as imagens das teorias psicológicas e pedagógicas com a criança. Não basta ter bom conhecimento teórico para saber como a criança é, pensa e age, pois corre-se o risco de não distinguir as imagens da criança universal elaboradas pelas teorias com a criança concreta. Ariès ( 198 I) revela que a criança, como categoria social, ainda é bastante recente na história da humanidade, pois gesta-se lentamente entre os séculos XIII e XVII. 
Aparece inicialmente na iconografia religiosa representando o anjo, o menino Jesus e a infância da Virgem Maria. Entre os séculos XV e XVI aparece em retratos, mas sempre ligada à vida do grupo como um todo nos quais era difícil separá-la do conjunto. No século XVIII, Rousseau reconheceu que a criança vive em um mundo próprio que deve ser compreendido pelo educador, pois não é um adulto em miniatura. Apesar do avanço trazido pelas idéias de Rousseau na representação da infância, o infantil permaneceu por muito tempo reduzido a uma mera etapa do desenvolvimento humano.

Lajolo (1997) assinala que as palavras infante, infância, e demais cognatos, em sua origem latina e nas línguas daí derivadas, recobrem um campo semântico estreitamente ligado à idéia de ausência de fala, qualidade ou estado daquele que não fala. Assim, a infância é sempre definida fora de si mesma e quando, por alguma circunstância, a palavra é passada à criança, emerge outro tipo de preconceito, pois os adultos acreditam que ela não sabe se explicar muito bem, faltandoIhe palavras, argumentos. Em decorrência disso, adultos acabam por colocar a criança no lugar daquele que não sabe, e de novo passam a deduzir como ela pensa e age. É difícil para nós educadores percebermos a criança, e também a nós mesmos, como seres que interagimos a partir de determinados espaços sociais e culturais, de onde emergem nossas vozes e nossos desejos.

A fim de conhecer o processo de formação permanente dessas professoras, indagamos sobre o período do último curso realizado. Neste estudo utilizamos a expressão formação permanente entendida como todas as formas deliberadas e organizadas de aperfeiçoamento profissional do docente, mediante palestras, seminários, encontros, grupos de estudo, oficinas, cursos presenciais e a distância. No grupo pesquisado, 4\% freqüentavam, naquele momento, algum curso; 25\% freqüentaram há um ano; 23\%, há dois anos; 13\%, há três anos; 4\%, há quatro anos; $13 \%$ terminaram-no de 5 a 10 anos; 7\%, de II a I 5 anos; 5\% não lembravam o período do curso realizado; $2 \%$ nunca haviam feito nenhum curso de atualização e $4 \%$ não responderam à questão.

Os cursos freqüentados pelas professoras foram organizados, em sua maioria, pela Secretaria de Educação do Estado, Projeto Nordeste, Proler, Instituto Anísio Teixeira, Universidade Estadual de Feira de Santana, Universidade do Estado da Bahia, Universidade Federal da Bahia e Universidade Católica de Salvador. Os cursos de atualização, com o objetivo de preencher as lacunas deixadas pela falta de sintonia entre a formação inicial e as necessidades do processo de ensino e aprendizagem dos estudantes, têm sido, quase que exclusivamente, organizados pela Secretaria de Educação do Estado. A participação das universidades ainda é 
pequena em relação à Secretaria, mesmo com a atividade cada vez mais intensa da Universidade Estadual de Feira de Santana e Universidade Estadual da Bahia em seus diversos programas de extensão.

As docentes avaliam diferencialmente esses cursos em relação ao trabalho que realizam: $41 \%$ julgam que, de alguma maneira, concorrem para a melhoria do desempenho, mas são muito vagas em precisar o tipo de contribuição, dando ênfase à ampliação dos conhecimentos pedagógicos e mais experiência; 19\% especificam que esses cursos cooperam para a aquisição de novas metodologias; 15\% declaram que a interação com os estudantes melhora após a realização do curso; 7\% consideram que esses cursos não colaboram para seu trabalho, porque estão fora da realidade ou porque duram muito pouco tempo; $6 \%$ alegam que os cursos aperfeiçoam o uso das tecnologias existentes na escola; $2 \%$ não lembram em que o curso contribuiu e $10 \%$ não responderam à questão. Percebemos que as professoras demonstram dificuldade em avaliar a eficiência desses cursos de atualização, ou seja, como eles se refletem na prática, nas situações do cotidiano, se o processo de ensino e aprendizagem vivido pelas professoras/estudantes se altera após a realização de um curso de atualização.

Sem dúvida, é necessário que as professoras tenham a oportunidade de crescimento para que os estudantes se beneficiem e possamos atingir a meta de uma educação centrada no ser humano e que priorize o aprender a aprender. Após refletir sobre os dados apresentados, suponho que deveríamos deslocar o eixo da discussão da formação do professor, centrada em uma rápida aquisição de conhecimentos e técnicas que conduzam ao bem ensinar, para uma ação cultural. Nós, professores, necessitamos de um espaço no qual não se discutirão apenas as importantes questões metodológicas do trabalho docente, mas que possibilitem o contato com os bens culturais. Dada a já consolidada tendência de deterioração das condições de trabalho dos docentes, nos encontramos privados da possibilidade de compartilhar os bens culturais produzidos por nossa sociedade. Se se pretende que o professor deixe de ser um executor de instruções uniformes, deve-se criar condições para que ele se familiarize com a criação cultural.

A criação cultural não se pergunta sobre que estágio de operações mentais, nem em que série se encontra o seu possível fruidor. A escola, bem como tudo a ela associado, está rigidamente apegada à idéia de adequação, de fases, níveis. Essa excessiva rigidez deixa a instituição escolar constantemente desatualizada. Enquanto nós, professores, nos perguntamos se certo filme deve ser passado nessa ou naquela série, o estudante está, quando pode, assistindo-o no cinema, em casa ou 
na vitrine de alguma grande loja. $\bigcirc$ mesmo acontece com as novas tecnologias, as descobertas científicas, os assuntos políticos, os eventos artísticos. É como se a escola só se interessasse pelo saber usar e não pelo saber fazer.

A forma pela qual o poder público enfrenta o desafio de oferecer uma educação de qualidade pode demonstrar o real envolvimento social com a questão, sobretudo, se se atenta para o fato de o serviço público ser o único a chegar aos setores menos favorecidos de nossa sociedade. Os sistemas com administração centralizada, que reservam às unidades escolares o papel de executoras de normas estabelecidas fora da escola, demonstram uma atitude na qual predomina a heteronomia sobre a autonomia. As tradicionais estratégias que priorizam a padronização de comportamentos e métodos de trabalho não têm apresentado resultados positivos, então por que conservá-las? Como formar leitores com professores não leitores? Como escutar as fantasias que crianças, adolescentes e jovens manifestam sobre inúmeros fatos do cotidiano, que poderiam gerar as mais diversas produções, se embotamos nosso próprio imaginário? Como estimular a criatividade, o raciocínio, a ousadia, se estamos tomados pela apatia? Como desenvolver a sensibilidade do estudante se a nossa própria sensibilidade é descuidada?

Para possibilitar a sensibilização do estudante, é necessário que o próprio professor se envolva com ampla gama de experiências artístico-culturais. Somente uma pessoa que mantém viva a curiosidade, parte fundamental dessa condição humana que é o desejo de conhecer, não apagará a qualidade em outras pessoas, senão seus procedimentos se tornam mecânicos. Nós, professores, necessitamos de um espaço que ofereça todas as mídias possíveis: livros, histórias em quadrinhos, CD-Rom, discos, revistas, vídeos, fotos, filmes, computadores, e muitas mais. Saber de química e televisão, cinema e biologia, teatro e música, matemática e literatura, usando, entre outros recursos, todos os bancos de dados com imagens das mais variadas interpretações capturadas via rede mundial de informações. Capturar, agarrar, apanhar, segurar, apoderar-se da oportunidade. Aprender e compartilhar nossas aprendizagens.

Não se trata de promover cursos ou oficinas, nem mesmo preservar os bens culturais, mas sim propiciar um espaço no qual se possa compartilhá-los como bens sociais que são. Não se trata de cultivar o espectador, o admirador, ou de formar um novo público de consumidores que apenas dispõe dos objetos, mas de oferecer condições para que esses professores tenham acesso ao êxtase, que lhes permita estar fora, sair de seu mundo cotidiano e experimentar o de outrem que é "antes de mais nada esta existência de um mundo possível" (Deleuze, Guattari, 1992, p.28). 
Alguns educadores argumentam que as propostas de formação permanente tendem a ser mais eficientes a partir das demandas dos docentes. Estudos como o de Veiga (1998) comprovam que a formação continuada deve considerar a experiência e a realidade profissional da pessoa e, assim, possibilitar uma reflexão sobre sua própria ação, suas potencialidades e limites. Instigamos essas docentes a proporem temas para cursos que considerariam como os mais importantes para o exercício profissional. Os temas que se destacaram são aqui relacionados em ordem decrescente por número de referências: Oficinas de Linguagens Específicas (música, teatro e artes plásticas); Objetivos da Arte; Metodologia; Dinâmicas e Vivências; Conteúdos e Planejamento em Arte; Arte seus Conceitos e Práticas; Interdisciplinaridade na Arte; Expressão Corporal; História da Arte; Folclores Regionais; Reciclagem com Sucata; Recuperar a Importância da Arte no Currículo; Arte do Brasil; Arte como Elemento de Transformação e Arte como Denúncia.

\section{CONDIÇÕES DE TRABALHO}

Entre as professoras pesquisadas, $4 \%$ atuam nos quatro primeiros anos do ensino fundamental; $2 \%$, nos oito anos e $94 \%$, nos quatro últimos anos. Quanto a exercer outra atividade além do magistério, 75\% não exercem outra atividade enquanto $25 \%$ dedicam-se a outro trabalho. Provavelmente essas serão as mesmas $25 \%$ que atuam em regime de 20 horas semanais. Fizeram a opção por 40 horas semanais $70 \%$ das docentes, e $5 \%$ responderam que atuam em regime de 60 horas semanais, ou seja, acumulam a função de professora em dois ou mais estabelecimentos de ensino.

O número de estudantes atendidos pelas professoras está na média de 330, sendo alocados em número de 39 por sala. Revelaram empregar, em média, 4 horas semanais no preparo de aulas e 4 horas na avaliação dos trabalhos realizados pelos estudantes. Para reuniões com todo o corpo docente da escola dispensam, em média, 3 horas semanais.

Entre as participantes da pesquisa $45 \%$ das professoras declararam que hoje escolheriam outra profissão. $\bigcirc$ salário indigno é o motivo pelo qual $75 \%$ das insatisfeitas deixariam o magistério e 25\% alegaram ser a desvalorização profissional e a falta de respeito com que se tem tratado o professorado. Em contrapartida, 55\% dessas professoras não fariam outra escolha profissional, e 42\% das satisfeitas justificam a opção profissional pelo amor que sentem pela profissão; $21 \%$, por ser gratificante poder ajudar o aluno; 20\%, por vocação e 17\%, por se encontrarem em final de carreira. 
Indagadas sobre o aspecto mais gratificante da profissão, as respostas se concentraram em torno das seguintes questões: a relação com o aluno, o seu carinho, o seu sucesso correspondem a 70\%; o convívio com os colegas, 10\%; o trabalho com a sensibilidade, 5\%; a descoberta das potencialidades dos alunos, 5\%; a possibilidade de colaborar com a construção da cidadania, 4\%; a percepção de que é possível mudar, 4\%; e 2\% declaram que nada é gratificante nessa profissão. Questionadas sobre o aspecto menos gratificante, $45 \%$ afirmaram ser a questão salarial, 19\%, o desinteresse dos alunos, 15\% das professoras estão insatisfeitas por trabalhar em espaço físico inadequado; 13\%, pelo excesso de alunos por sala e 8\% alegam o desrespeito pela disciplina Educação Artística.

O contexto socioafetivo que envolve o exercício do magistério emerge como fonte de satisfação e insatisfação. A falta de interesse das crianças, apontada como aspecto frustrante pelas professoras, não será uma resposta dessas crianças às condições que thes são oferecidas no ambiente escolar? Sabemos que o sistema estadual de ensino está longe de atender as necessidades dos estudantes e da sociedade, porém criar um ambiente estimulante e adequado à aprendizagem significativa é, também, função da professora e como criar essas condições se não estamos motivadas para tal? A questão da aviltante remuneração das professoras surge uma vez mais. Se o salário era motivo para boa parte das professoras escoIherem outra profissão, na última questão ela surge como aspecto mais frustrante para as docentes em exercício. Compartilho com essas professoras o sentimento de dificuldade em encontrar fontes de satisfação nas precárias condições de carreira e trabalho que se traduzirão nos próximos parágrafos.

Procuramos verificar quais as dificuldades que encontram no cotidiano da escola para a realização do trabalho com Arte. Entre as respostas, 30\% agruparam-se em torno da falta de material didático e material adequado; 26\%, no espaço impróprio e a necessidade de uma sala ambiente; $12 \%$ julgaram ser a grande dificuldade o excesso de alunos por sala enquanto que outros $11 \%$ atribuíram à falta de interesse do aluno; $7 \%$ reconhecem a falta de formação adequada na área de conhecimento com a qual trabalha; 6\%, na dificuldade existente para o acesso à arte; 4\%, a situação financeira do aluno, e outros 4\%, na desvalorização da disciplina Educação Artística.

Nessas respostas parece-me relevante o fato de que apenas 7\% das professoras, em quase sua totalidade (95\%), não possuindo formação específica, reconhecerem suas próprias limitações como dificuldade para a efetivação do trabaIho em sala de aula. A maioria das professoras atribuiu as dificuldades à escassez de recursos físicos, materiais, ao excesso de alunos e à falta de interesse desses pelo 
tema. Chegaram a mencionar até mesmo a situação financeira dos estudantes sem questionar a insatisfatória formação para a responsabilidade que assumiram com a disciplina Educação Artística.

Diante das dificuldades vividas no cotidiano escolar, indagamos sobre as atividades que as professoras gostariam de efetivar em benefício de suas escolas. Uma Feira de Cultura e Arte seria realizada por 23\% das professoras; $21 \%$ implantariam uma sala ambiente; I I \% não responderam enquanto $9 \%$ não executariam nenhuma atividade. Montar um cantinho de leitura, uma biblioteca, reuniu $7 \%$ das pesquisadas; outros $7 \%$ desenvolveriam projetos com a comunidade; $6 \%$ organizariam palestras com artistas, $4 \%$ trabalhariam com vídeos da tevê escola; 4\% gostariam de trabalhar de forma mais prática; $4 \%$ fariam atividades que desenvolvessem uma maior interação entre os professores e outros $4 \%$ inaugurariam um núcleo de assistência ao estudante no qual ele pudesse falar o que necessita.

A escolha de atividades que gostariam de realizar em benefício da escola reflete as precárias condições de trabalho, mas também expressa desejos possíveis de realização. A reivindicação da sala ambiente, por exemplo, pode ser arranjada com um ajuste de distribuição espacial, tal como várias escolas públicas de outros estados já adotaram. Trabalhar com vídeos da tevê escola, desenvolver atividades mais práticas e com maior interação entre os professores são atividades ao alcance dessas professoras. Por que elas se mantém no condicional?

\section{CONCEPÇÕES SOBRE O TRABALHO DE ARTE}

Ao interpretarmos as respostas a respeito do tipo de conhecimento que caracteriza a Arte e suas funções na escola, poderíamos agrupar as referências em torno de categorias, como conhecimento, expressão emocional, prazer estético, comunicação ou entretenimento. Tal quadro, porém, seria contrário à idéia de síntese da Arte, já que a arte é conhecimento, expressão emocional, prazer estético, representação do mundo, comunicação, entretenimento e muito mais. Assim, o que se buscou foi indicar a categoria emergente das respostas das professoras que será apresentada sem uma classificação quantitativa rigorosa para não perdermos a visão do todo.

Indagadas sobre que tipo de conhecimento caracteriza a Arte, emergiram as seguintes respostas em ordem decrescente de referências: emoção, intuição, expressão corporal, conhecimento científico-tecnológico, conhecimento técnicofilosófico, liberação dos sentimentos, conhecimentos gerais, conhecimento do cotidiano, conhecimento emotivo, expressão de sentimentos, leitura do mundo, sen- 
sibilidade, criatividade, autoconhecimento, expressão dos sentimentos, imaginação, o pensarffazer/criar.

A concepção que prevalece entre as professoras é a de ser a Arte uma expressão pessoal de sentimentos e a criação artística resultado do afeto e da emoção. Em contrapartida, essas mesmas professoras afirmaram ser a função da Arte na escola passar qualquer conteúdo escolar, comemorar, preparar as festas, desenvolver a capacidade motora, melhorar a disciplina e a atenção. Enfaticamente, referem-se à Arte como um dom que se desenvolve naturalmente, uma coisa que já nasce com o menino.

Sem dúvida, a arte é auto-expressão, como se percebe no entendimento das professoras, mas é também uma forma de conhecimento que favorece o desenvolvimento intelectual. Como qualquer outra área do conhecimento, possui conteúdos próprios capazes de estimular situações adequadas à construção de conhecimento aliado à produção artística. Fusari e Ferraz (1992) afirmam que o sucesso de um processo transformador no ensino da Arte depende de um professor cuja prática teórica do saber e do fazer artístico deve estar conectada a uma concepção de Arte e propostas pedagógicas consistentes. Esse professor precisa saber Arte ao mesmo tempo em que necessita saber ser professor. $\bigcirc$ professor de Arte deve aprofundar seu conhecimento estético (compreensão e conhecimento dos legados culturais e artísticos da humanidade unindo o fazer e o refletir, o "pensar o que faz") e artístico (vivência das linguagens específicas) e desenvolver uma prática pedagógica que aproxime o estudante do conhecimento cultural e artístico de sua própria e demais culturas.

Os dados apresentados nesta pesquisa indicam professores distantes das características sinalizadas por Fusari e Ferraz (1992). Temos professoras que para complementar suas horas de trabalho se responsabilizaram por um conteúdo sem terem uma formação para tal e que ainda não buscaram suprir essa lacuna. Poderíamos classificá-las como professoras leigas simulando o trabalho de uma professora de Arte. Professoras com uma concepção instrumental de Arte, pois entendem-na como atividade auxiliar, recreativa, como meio para alcançar outros fins e não pelos valores que ela possui em si mesma. Essas professoras que, por via de complementação de carga horária, foram obrigadas a preencher suas horas/aulas com o pouco tempo previsto para a Educação Artística, sem terem tido algum preparo nesse sentido, tampouco buscaram aprofundar seu conhecimento estético e artístico. Esse fato, somado às duas horas semanais dedicadas à Arte, mais a falta de espaço e material adequado nas escolas, além do elevado número de estudantes em cada sala, nos leva a concluir que o horizonte de qualidade propos- 
to pelos Parâmetros Curriculares Nacionais não será atingido apenas com sugestões de propostas curriculares.

Para a efetiva consolidação das valiosas contribuições do documento oficial, falta-lhe uma política complementar adequada para alcançarmos a qualidade do ensino e da aprendizagem. Entendo tal política como uma estratégia de intervenção governamental que inclua a formação do professor de Arte, além de proporcionar condições materiais para a realização de seu trabalho. Nesse ponto, concordo com Morin ao afirmar que oferecer mais recursos materiais aos professores e escolas não garante a necessária reforma do pensamento, porém sem esses recursos a reforma tampouco é garantida (Silva, 1998).

A escola brasileira pode atuar para a democratização do acesso à Arte se trabalharmos para a familiarização, a intimidade para com as diferentes linguagens artísticas e se construirmos nossos esquemas de percepção e compreensão dos elementos básicos de cada uma delas. Com o corpo docente que dispomos no momento, o trabalho de Arte se resume a pequenas noções de artesanato feito, sobretudo, com sucata. Por serem tão superficiais, inconsistentes e nada significativas, as atividades artísticas exploradas nas escolas pesquisadas ratificam a idéia de que a Arte é uma atividade para os bem dotados; como se a criatividade e os esquemas de percepção e apreciação não fossem socialmente construídos. Nossas professoras entendem Arte como dom, hobby, pois, tampouco, tiveram a oportunidade de desenvolver suas capacidades para apreciar, conhecer, pensar e fazer Arte não só por não possuírem uma formação específica, mas, também, por viverem em uma sociedade marcada por uma desigual distribuição de bens materiais e simbólicos.

Fazer Arte em qualquer espaço pressupõe o exercício coordenado de pensamento/intuição/sensibilidade/ımaginação. Fazer Arte é fomentar a capacidade de criar imagens que está na raiz de qualquer processo de conhecimento. Fazer Arte no precário contexto escolar brasileiro pode parecer, para muitos, impossível, inviável, porém manter essa impossibilidade perpetua o conservadorismo que tem caracterizado nossa cruel lógica da exclusão.

\section{REFERÊNCIAS BIBLIOGRÁFICAS}

ARIÈS, P. História social da criança e da família. 2. ed. Rio de Janeiro: LTC, I98I.

BRASIL. Lei n. 9.394, de 20 de dezembro de 1996: Estabelece as diretrizes e bases da educação nacional. Diário Oficial da União. Brasília, v. 134, n. 248, p. 27.833-42, dez. 1996. 
1997. Parâmetros Curriculares Nacionais. arte (5ª a $8^{\mathrm{a}}$ séries). Brasília: MEC/SEF, 1998.

DELEUZE, G.; GUATTARI, F. O Que é a filosofia? Rio de Janeiro: Ed. 34, 1992.

ENGUITA, M. A Ambigüidade da docência: entre o profissionalismo e a proletarização. Teoria e Educação. n. 4, p.4I-61, 1991.

FREITAS, M. C. de (org.). História social da infância no Brasil. São Paulo: Cortez, 1997. p. 225-45.

FUSARI, M. F. R.; FERRAZ, M. H. C. Arte na educação escolar. São Paulo: Cortez, 1992. GIL, A. C. Métodos e técnicas de pesquisa social. São Paulo: Atlas, 1987.

LAJOLO, M. Infância de papel e tinta. In: FREITAS, M. C. (org.). História social da infância no Brasil. São Paulo: Cortez, 1997. p. 225-45.

ROUSSEAU, J.-J. Emilio ou da educação. São Paulo: Difusão Européia do Livro, 1968.

SILVA, J. M. O Elo mais frágil. Folha de São Paulo, Caderno Mais, p. 13, 10 maio 1998.

VEIGA, I. Caminhos da profissionalização do magistério. Campinas: Papirus, 1998. 